\title{
GEOGRAPHIC INFORMATION SYSTEM AND REMOTE SENSING BASED DISASTER MANAGEMENT AND DECISION SUPPORT PLATFORM: AYDES
}

\author{
İ. Keskin ${ }^{1 *}$, N. Akbaba ${ }^{2}$, M. Tosun ${ }^{3}$, M.K. Tüfekçi ${ }^{4}$, D. Bulut ${ }^{5}$, F. Avc1 ${ }^{6}$, O.Gökçe ${ }^{7}$ \\ Republic of Turkey, Prime Ministry, Disaster and Emergency Management Authority (AFAD), Ankara, Turkey \\ 1 irfan.keskin@afad.gov.tr \\ 2 nihan.akbaba@afad.gov.tr \\ ${ }^{3}$ murat.tosun@afad.gov.tr \\ ${ }^{4}$ mkemal.tufekci@afad.gov.tr \\ 5 dogus.bulut@afad.gov.tr \\ ${ }^{6}$ fatih.avci@afad.gov.tr \\ 7 oktay.gokce@afad.gov.tr
}

KEY WORDS: Disaster Management, Decision Support System, Geographic Information System, Remote Sensing, AYDES

\begin{abstract}
:
The accelerated developments in information technology in recent years, increased the amount of usage of Geographic Information Systems (GIS) and Remote Sensing (RS) in disaster management considerably and the access from mobile and web-based platforms to continuous, accurate and sufficient data needed for decision-making became easier accordingly.

The Disaster Management and Decision Support System (AYDES) has been developed with the purpose of managing the disaster and emergency management processes effectively and creating a management model based on an IT infrastructure and a decision support system required for both pre-disaster risk reduction \& preparation and post-disaster respond \& recovery stages. The system is a holistic platform integrated with many internal and external systems and services, including desktop, mobile and web-based applications that utilize GIS and RS technologies. AYDES has been prepared especially according to the content of the National Disaster Response Plan of Turkey and designed to be easily used by the Disaster and Emergency Management Authority (AFAD), collaborative Ministries, private institutions and provincial organizations. AYDES is an integrated framework enabling the execution of processes effectively. AYDES already has approximately 6,200 active users from the central and provincial organizations of AFAD and other public institutions and organizations.
\end{abstract}

AYDES consists of three core components with their sub components, namely "Incident Command System", "Spatial Information System" and "Recovery Information System". Mobile software tools that can deliver real-time information to the web-based core components of AYDES that consists of applications used for mapping during both post-disaster damage detection and pre-disaster risk reduction. Additionally, in case of a need to disaster event inventories, potentially vulnerable assets, hazard - risk data, affected areas of probable or actual disasters, damage detection results and such data and analyses, two software tools have been developed, namely AYDES-RS, a desktop image processing and analysis software and AYDES-CS, a web-based crowdsourcing software tool whereas two of them enable to allow the use of imagery acquired by remote (space/aerial) technologies for various analyses before and after a disaster. AYDES is a software, data and analysis platform that provide accurate and current disaster and emergency data, reports, statistics, job inspections, queries, analyses etc. at every stages before and after the disaster.

\section{INTRODUCTION}

Disaster Management and Decision Support System (AYDES) is an information system which is developed for performing the processes of disaster and emergency management efficiently. The system is an integral platform connected to other internal and external systems and applications and composed of desktop software, GIS based web applications (2D and 3D) and mobile applications. AYDES is prepared properly to the content of Turkey Disaster Response Plan (TAMP). The system presents a holistic approach for effective and easy usage in disaster management processes and is designed to be used by Disaster and Emergency Management Presidency (AFAD), relevant ministries and provincial organizations. AYDES consists of three main components as "Incident Command System", "Spatial Information System", "Recovery Information System" and subcomponents belong to these (Figure 1).

* Corresponding author

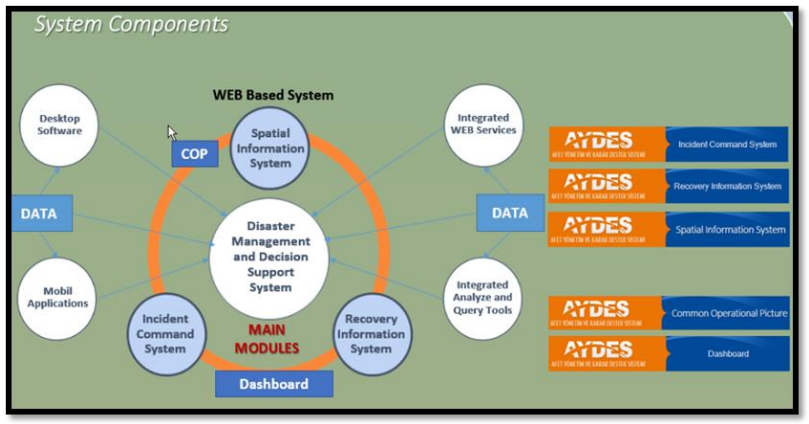

Figure 1. System components of AYDES

Mobile software tools that can deliver real-time information to the web-based main modules are developed in accordance with the field data collection and consist of applications used in mapping studies within the scope of risk mitigation as well as post-disaster damage detection. In addition, disaster event 
inventories, potentially vulnerable assets, hazard - risk data, areas of probable or actual disasters, etc. AYDES-RS "desktop image processing and analysis software and AYDES - Crowd Sourcing software have been developed for the use of remote (space / air) sensing technologies in various analyses before and after disasters.

AYDES is a software and data platform that provide accurate and current disaster and emergency data, reports, statistics, job inspections, queries, analyses etc. at every stages before and after the disaster.

\section{MAIN COMPONENTS}

The main features and scope of the AYDES main components are summarized below.

\subsection{Incident Command System}

Incident Command System (ICS) is an AYDES component which allows the holistic management of the processes of disaster preparation, planning and response phases that are described in TAMP. Software based management model supports disaster and emergency preparedness and response activities at the local and national level through the main management processes (resource management, transport, demand management) flexibly and effectively. When a disaster event occurs at national or local level, event notifications can be sent to teams by SMS and e-mail so that via the instant messaging and e-mail, service groups (defined as part of TAMP) can remain in continuous interaction and communication. Data pool and data analysis framework was set up so that 28 service groups could process the processes related to their own specialization fields and data that could be needed in the management of service groups could be entered into the system during various stages of disaster.

Sub-menus in ICS are as follows: (1) Incident identification and listing, (2) Organization structure, (3) Address book, (4) Facility management, (5) TAMP documentation, (6) Service Group Recovery procedures, (7) Resource management, (8) Demand management, (9) Transportation and transfer operations, (10) Scenario panel, (11) Identity management, (12) Message box, (13) Notifications, (14) Reports, (16) My Account. Figure 2 shows the menus and sub-menus of AYDES.

ICS is designed according to the content of TAMP. A postdisaster use of ICS can be summarized as follows. After a disaster, the need estimate is automatically calculated by AYDES ICS using the information obtained from the disaster area. According to the TAMP, service groups system is transferred to the disaster area in accordance with the notification sent to them automatically by the system. Search and rescue teams demand the equipment they need from the system. The tasks and transactions of service groups carried out within the scope of the tasks and responsibilities, what requests are made, whether they are met or not and all response operations are monitored and can be monitored and reported in real time from the system. Figure 3 shows the ICS.

Figures 4 shows the dashboards of ICS for the number of total evacuated, identity determination status and injured information.

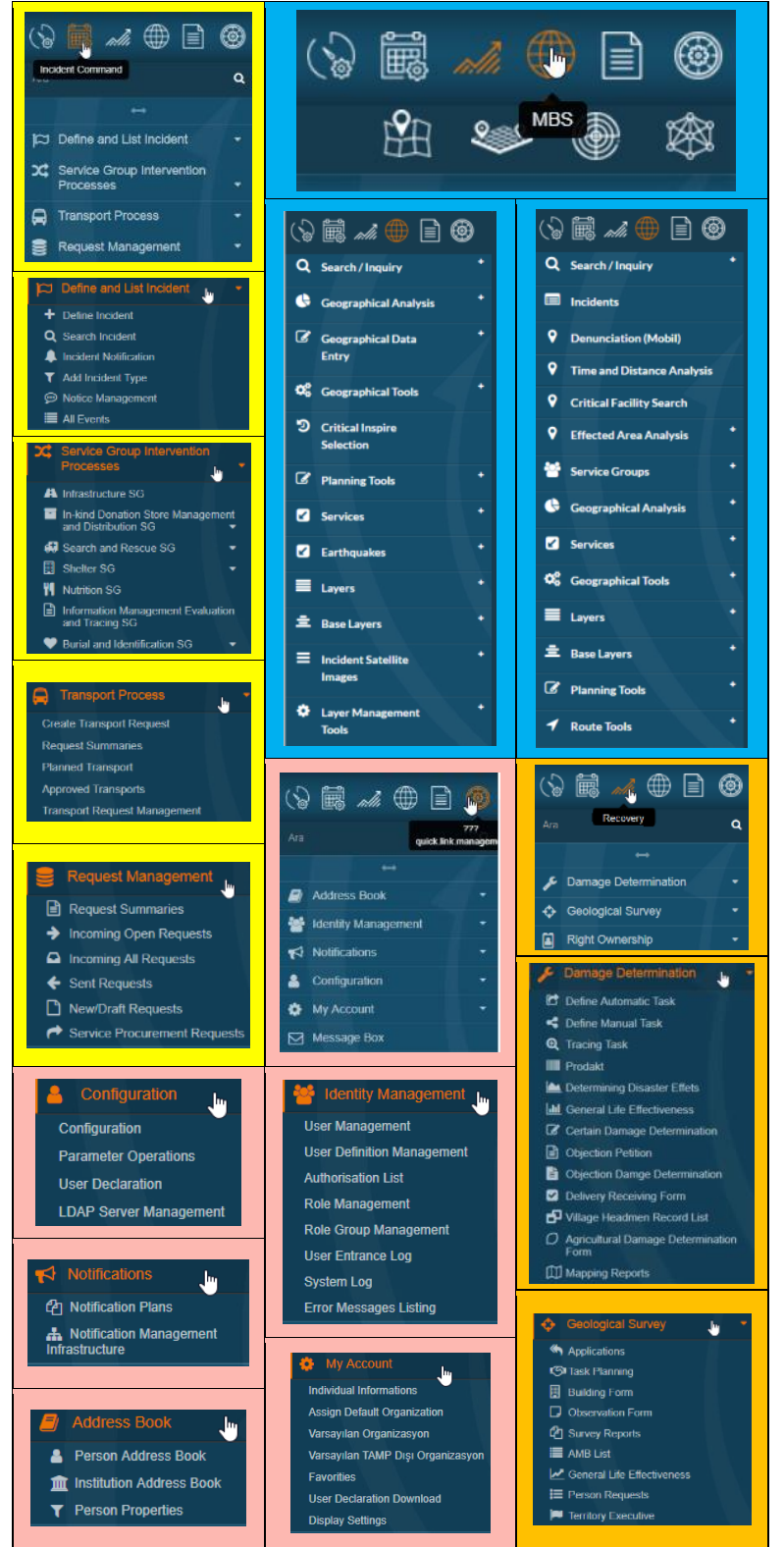

Figure 2. Menus and Sub-menus of AYDES

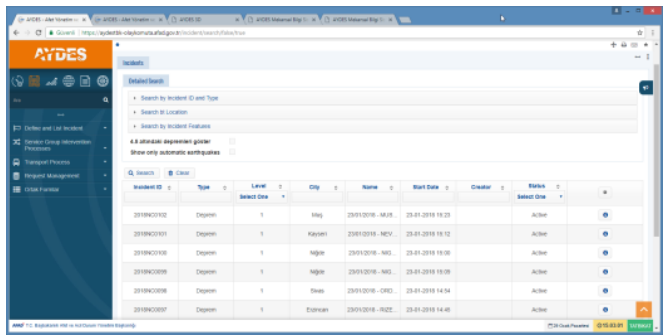

Figure 3. Incident Management System of AYDES

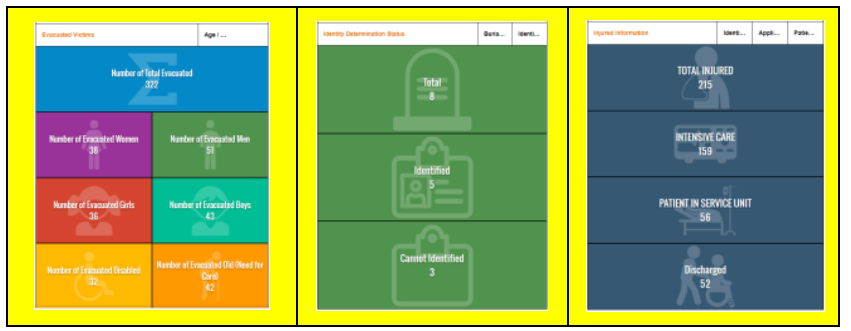

Figure 4. Dashboards of Incident Management System 
A total of 4442 events were entered in AYDES using Incident Command System in 2017. This shows that AFAD responds on an average of more than 12 disasters every day. Figure 5 shows the monthly numbers of incident records for the year 2017 and Figure 6 shows the most disaster and emergency types recorded in 2017.

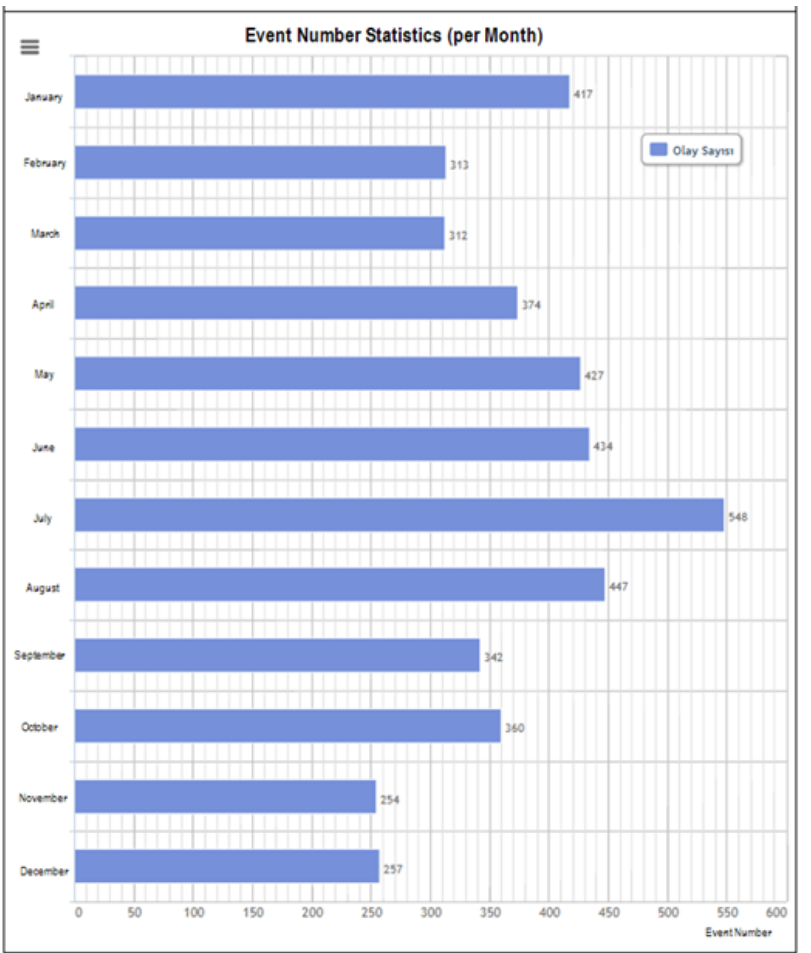

Figure 5. The monthly numbers of incident records in 2017

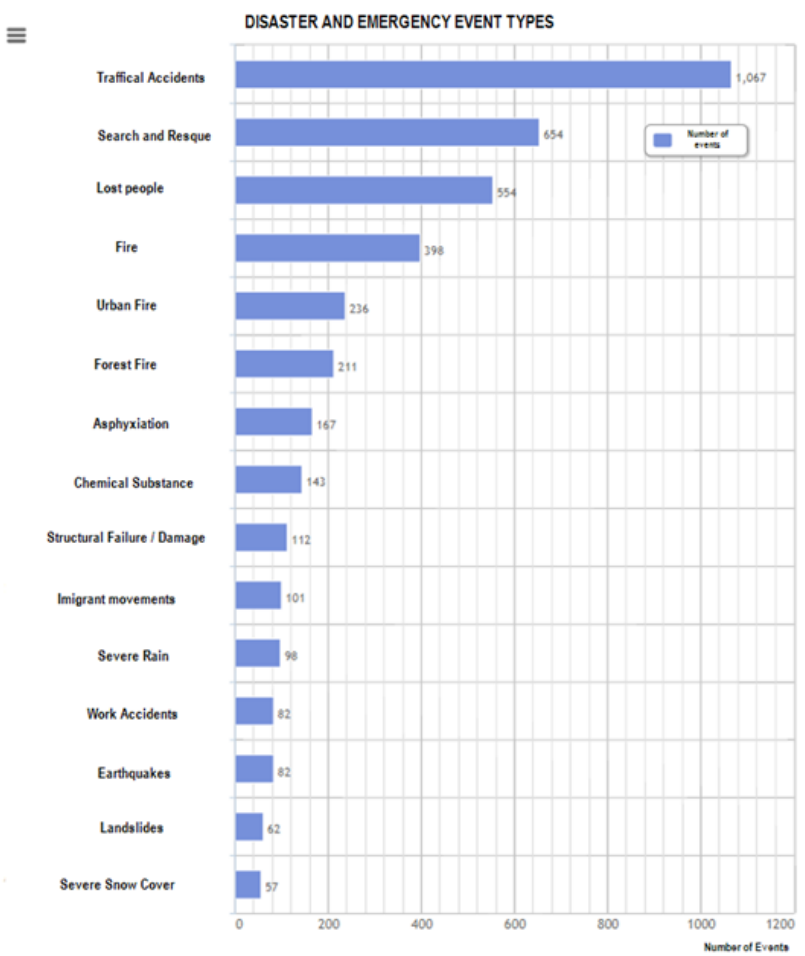

Figure 6. Most disaster and emergency types recorded in 2017

\subsection{Recovery Information System}

Sub modules of the RIS developed already are as follows:
- Damage Assessment

- Geological Hazard Survey

- Beneficiary Management

The other sub modules of the RIS to be developed are as follows:

- Resettlement Site Selection

- Investment Program

- National Emergency Assistance and Tracking

The outputs the "Damage Assessment" sub module are used as input to the Beneficiary Management sub module of RIS.

Recovery Information System (RIS) aims to realize post disaster recovery activities in electronic environment with GIS support. Thus, consistency between the different recovery stages (damage determination, geological surveys, right ownership and debiting, resettlement site selection, investment program and national emergency assistance and tracking) that produce input for other stages will be ensured and incorrect operations caused by repeated or wrong data records- will be prevented. Also, system allows the collection of data by mobile applications from field and near real time location based post disaster data are presented for decision makers and other users of the system. Figure 7 shows the relationship diagrams between RIS sub modules and TAMP damage detection sub module.

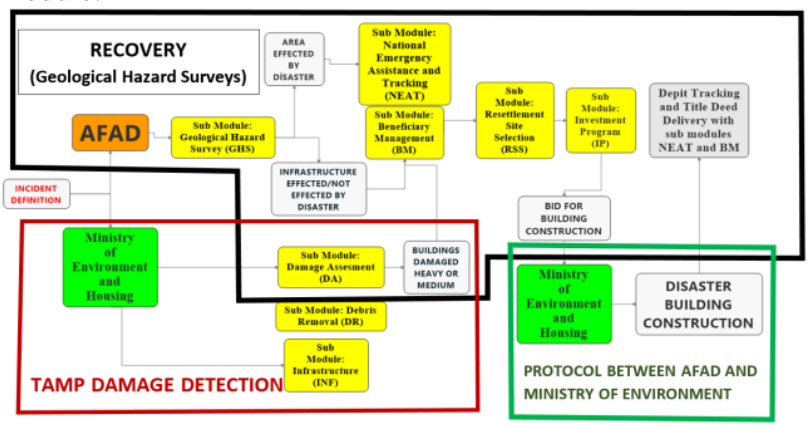

Figure 7. Relationship diagrams between RIS sub modules and TAMP damage detection sub module

\subsubsection{Damage Assessment Sub Module}

With this module, after the earthquake, flood and fire disaster events are defined, the technical teams are assigned to the site and the damage level of the structures (houses, work places, barns, etc.), information about location, owners and tenants of these structures are acquired via web and mobile applications. The owners of heavy and moderately damaged structures are considered to be victims of disaster (possible beneficiary candidates). This information provides input data to the entitlement and beneficiary management module. This information is also used in permanent settlement construction, housing and rent aids (Figure 8).

\subsubsection{Geological Hazard Survey Sub Module}

With this module, the ground and building conditions are analysed together after identifying any disaster events. After the event is defined, all insensitivities in the field caused by landslide, avalanche, flood, earthquake, fire etc. are mapped and areas affected by disaster are marked on the map using web and mobile applications. The location, the owner and the tenant information of the buildings in the areas affected by disaster are 
collected via the interfaces of this module. This information provides input data to the entitlement and debit module. This information also provides input data to the entitlement and debit module. This information is also used in housing, housing and rent aids.

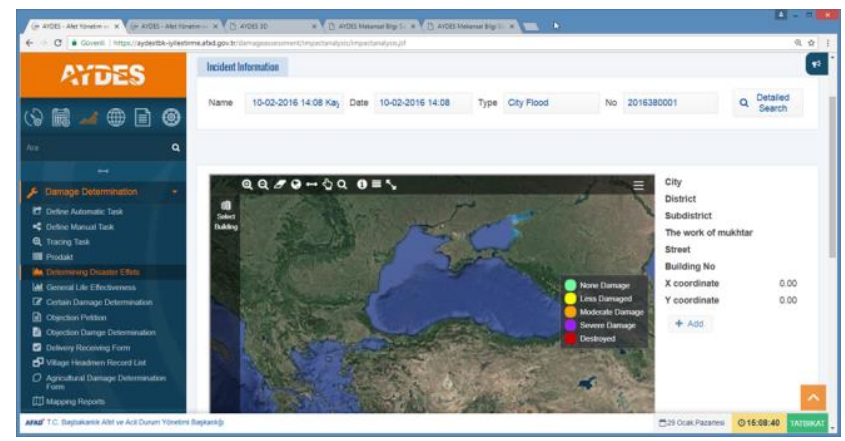

Figure 8. AYDES-RIS Damage Determination Sub Module

\subsubsection{Beneficiary Management Sub Module}

With this module, Beneficiary Management commission, created by AFAD's provincial directorate, evaluates the beneficiary management of the disaster victims using the outputs of damage assessment and geological hazard survey modules. After evaluation, they prepare and approve the name lists of the beneficiary disaster victims. Disaster victims who are deemed as beneficiary shall be debited for no interest for a period of 20 years. With this module, repayment of debits is also followed.

\subsubsection{Resettlement Site Selection Sub Module}

For the victims of disasters, it is the module where the safe residential areas are searched, identified and selected for settlement planning and construction. In the determination of new settlement areas, General Directorate of State Hydraulic Works, General Directorate of Forestry, institutional remarks are collected. The settlement zoning plans, cadastral plans and land registries of the possible settlement areas to be selected are evaluated. If there is no zoning plan in new settlement areas, zoning plans will be created by taking geological and geotechnical survey studies after mapping the current situation. Site selection report is prepared after technical studies.

\subsubsection{Investment Program Sub Module}

The entitlements to be placed in the new settlement areas where the site selection report is prepared are taken to the investment program list. This list also includes methods of housing construction (e.g. household assistance, tender, TOKI, etc.). Allocation is requested from the Ministry of Development for the beneficiaries of the investment program. It is the module of the works done up to the delivery of the houses made by the above mentioned housing construction methods. In addition, this module is used to list the excess land and houses.

\subsubsection{National Emergency Assistance and Tracking Sub Module}

Using this module, in accordance with Law No. 4123 on the Execution of Services Related to Natural Disasters Due to Natural Disasters, carrying out are the services that will provide the normal life for the areas affected by the disaster and the requests made in the Governor's offices for the removal of damage and destruction were followed.

\subsection{Spatial Information System}

"Spatial Information System" (SIS) is the supplementary part of the whole work to build a sustainable disaster management and decision support system by using geographical information system (GIS) technologies. Spatial data - which can be used in disaster and emergency management - were collected in physical environment or by web services from different governmental or non- governmental agencies to create a geodatabase as part of SIS. It is designed for accurate and quick decision making by spatial queries and analysis with existing and contemporaneously added data pre-disaster, during disaster and post-disaster activities. Subcomponents and menus of the application provide to update, edit and query of the spatial data as real time and allow to view and report the final results. The "Common Operation Picture" (COP), which has basically the same design and common features as the SIS (MBS in Turkish), is an additional component that displays and reports on work and results, especially with respect to the stage of the response to the disaster. Under COP, real-time information from AYDES components is planned to be generated instantaneously by means of this information.

\subsubsection{Layers of geographic database that have been created through SIS}

\section{- INSPIRE layers:}

(1) Land use cover, (2) Buildings, (3) Geographical grid systems and map indexes, (4) Geographical structures, (5) Energy resources, (6) Hydrography, (7) Administrative units, settlements, addresses, (8) Geology, (9) Public services, (10) Protected private areas, (11) Population distribution and demography, (12) Agriculture, (13) Transportation Networks, (14) Industrial areas, (15) Topography.

\section{- FACILITY layers:}

(1) Finance, shopping and trade, (2) Sheltering and accommodation, (3) Educational institutions, (4) Critical substructure and superstructure, (5) Public institutions, (6) Health facilities, (7) Industrial and manufactural points, (8) Non-governmental organizations, (9) Socio-cultural facilities, (10) Historical and touristic structures, (11) Telecommunication and media, (12) Transportation facilities, (13) Food, drink and amusement places, (14) Green zones.

\section{- AFAD layers:}

- Disaster prevention and response sub layers:

(1) AFAD and AADYM units, (2) Sheltering, (3) Food production units and facilities, (4) Distribution points, (5) Burial service areas, (6) Warehouses, (7) Debris removal, (8) Food, agricultural and farming, (9) Security and traffic, (10) Communication, (11) Service groups and logistic, (12) Health cares, (13) Technical support and supply, (14) Assembly areas, (15) Warning and alarming points, (16) Fires, (17) Routes to AFAD logistic warehouses of city centres.

- Disaster inventory-Danger - Risk Zones Sub layers:

(1) Earthquake (2) Faults, (3) Landslides, (4) Rock fall, (5) Floods, (6) Risk Maps, (7) Technological disasters, (8) All disaster inventories (point), (9) Avalanches. 


\subsubsection{Main characteristics of the SIS sublayer}

- Map Tools: with map tools you can use functions such as get info, zoom in, zoom out, clear map, layer control, active layer, go to coordinate, preview window, scale tool, coordinate system selection tool.

- Address Search Bar: provides an option to search for an address or facility on the map.

- Search \& Query Menu: provides an option to make an inquiry from disaster preparation data, structural data, inspire data and also from the events that occurred.

- Geographic Analysis Menu: makes an inquiry by creating a buffer zone for disaster preparation and some analysis processes such as proximity analysis, linear proximity analysis, inspire buffer zone analysis and analysis by drawing inspire areas.

- Geographical Data Entry Menu: provides an option to entry geographical data to layer of buildings, disaster inventory risk zones, also primary damage and primary influence area risk analyses.

- Geographical Tool Menu: provides an option to load data and to view kml, shp files.

- Services Menus: provides an option to reach services such as YAHOO meteorology, EUMSTAT, KGM, YUVAM, TRAFFIC WFS, AFKEN tent areas and AFAD logistic warehouses.

- Earthquakes Menu: provides an option to view all earthquake information on the map which have been supplied by Earthquake Department of AFAD.

- Layers Menu: provides an option to reach layers of orthophoto, vector tile, Google earth, Bing aerial, Turksat Satellite, World imagery, Landsat 2000.

- Event Dependent Layer Menus: provides an option to matchup event dependent layers and to view layers that matchup depending on events.

- Layer Management Tools: provide an option to view the metadata of layers.

- Events menu: provides an option to search for disaster and emergency situations and locate them on map.

- Time Chart: provides an option to search for disaster and emergency situations and locate them on map.

- Service Groups Menu: provides an option to view the special info of data that have been entered by command module of COP module.

- Planning Tools Menu: provides an option to make geographical planning on map and record it.

- Route Tools: provide an option to determine and draw the route between two locations by selecting start $\&$ finish points on the map.

- Preliminary Impact Analysis/Preliminary Damage Locating Menus: provide an option to view the estimated distribution of earthquake damage made by AFAD-RED, the remote sensing analysis results, the analysis of damaged buildings.

\subsubsection{Web services Through SIS component}

- REGISTRY \& CADASTER (integrates spatial land/parcels data to SIS by using title parcels services and land registry)

- KGM (displays the roads that are closed or under construction with the help of web services supplied by the General Directorate of Roads)

- GEZGIN (connects to services that shows metadata and coverage service Ares of RASAT satellite images.)

- TRAFIK WFS (integrates up-to-date data of traffic situation, roads, real-time speeds and speed limits in Turkey that have been acquired by Başarsoft web services by using 4 different colours according to the traffic density)

- NVİ-UAVT (connects National Address Database (UAVT) to SIS to locate the address of the user)

- METEOROLOJI (integrates weather forecast that have been acquired by meteorology to SIS.)

- YAHOO (integrates YAHOO weather forecasts data to SIS.)

- EUMETSAT (integrates EUMETSAAT weather forecasts data to SIS)

- GOOGLE SATELLITE (integrates Google Satellite data)

- GOOGLE PHYSICAL (integrates Google satellite, Google Street, Google physical data)

- GOOGLE STREET (integrates Google Street data)

- BING SATELITE (integrates BING satellite maps)

- TÜRKSAT (integrates TURKSATMAPS satellite, physical, land data)

- VECTOR TILE (integrates vector tile maps to SIS.)

- VECTOR LAYERS (integrates vector layer maps to SIS.)

- ORTHO-PHOTO (integrates raster data that have been acquired by General Directorate of Registry and Cadaster (TKGM) in 2009,2010,2011,2011,2013)

\section{- WORLD IMAGERY (views the ESRI map layers)}

- LANDSAT 2000 (integrates Landsat satellite images)

- SETTLEMENT SUITABILITY SERVICE (integrates the data of settlement sustainability areas that acquired by settlement sustainability service which were created by settlement sustainability (YUVAM) project)

- DISASTER AFFECTED ZONES SERVICE (integrates the data of disaster affected zones that have created by settlement sustainability (YUVAM) project)

- AFKEN TENT POINTS (integrates the data of tent points that acquired by AFKEN web application)

- CONTAINER TRACKING (integrates the data of container tracking that have been acquired by logistic warehouse systems applications)

- AFAD LOGOSTIC WAREHOUSES (integrates the spatia data of AFAD logistic warehouse layers with their attributes) 
Although SIS and COP menus look alike, they differ in purpose of use and user profiles. COP is a supplementary component for disaster response. Disaster and emergency events that have happened in our country can be viewed by these component. Both components have analysis and query modules. Flood domains, real-time estimations of seismic intensities of earthquakes that happened, interpretation, analyses and queries can be made by these components. Screenshots of components of SIS and COP are shown in Figure 9.
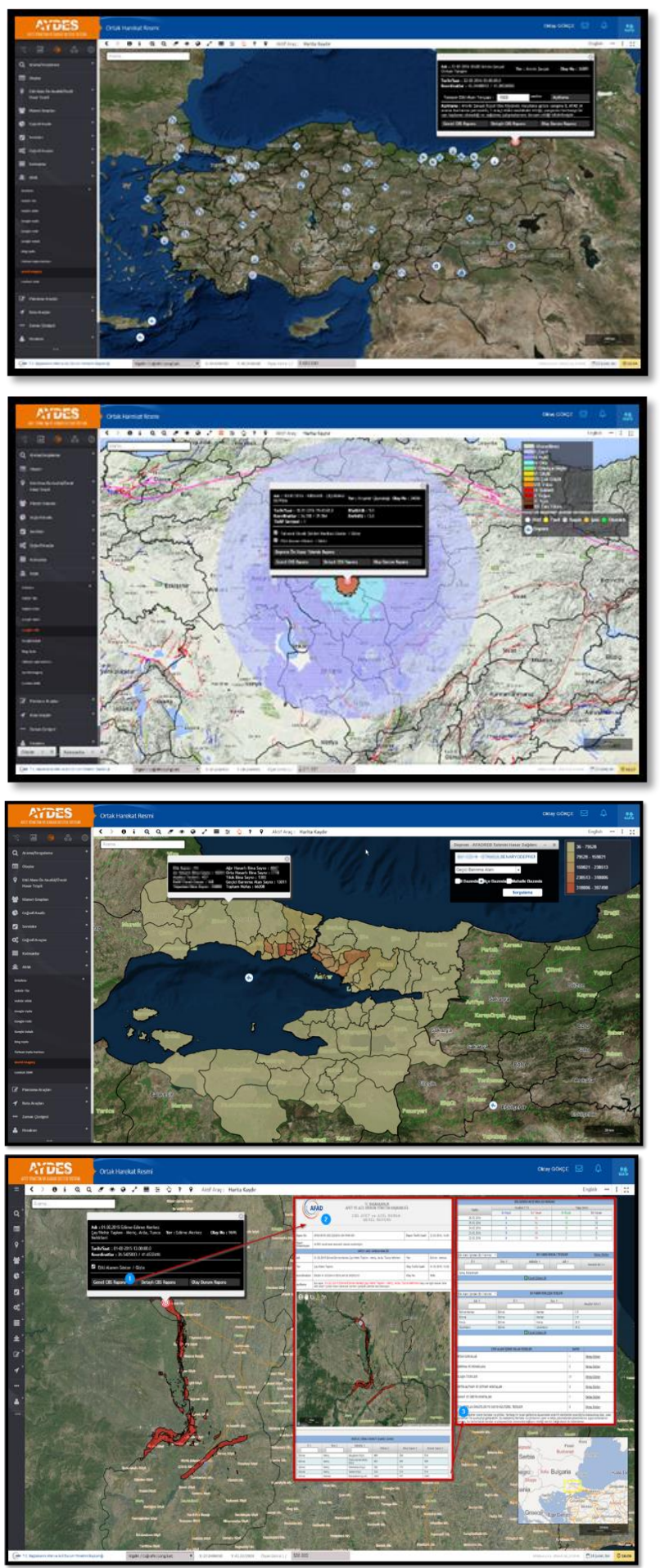

Figure 9. SIS and COP components of AYDES

\subsection{Mobile Applications}

After the disaster, depending on the type of disaster, damage detection data related to the disaster area and disaster event inventory (landslide, rock fall, avalanche) data can be gathered by mobile applications quickly and efficiently. With mobile applications, data can be collected offline while offline data can be transferred to AYDES as soon as the Internet connection is available. In addition, All the information such as where the field teams are, what activities they are doing, their task completion stages, etc. can be monitored from the related map screens in the AYDES components. The mobile applications developed in this context are as follows:

- Disaster Event Inventory Data Collection Mobile Application: Spatial data related to disaster events such as landslide, rock fall and avalanche (landslide area, rock fall source-spread area, falling blocks, avalanche areas etc.) and descriptive data (feature attribute values) can be collected online and off-line by this mobile application. The roads, points of interest (parks, public institutions, shopping centres, industrial areas, etc.), topographic maps, geological maps and satellite images (in on-line mode) as well as provincial, district and neighbourhood border data can be used as base layers. The collected data can be displayed in the main component of the SIS in real time. Figure 10 shows screenshots of this Disaster Event Inventory Data Collection Mobile Application.
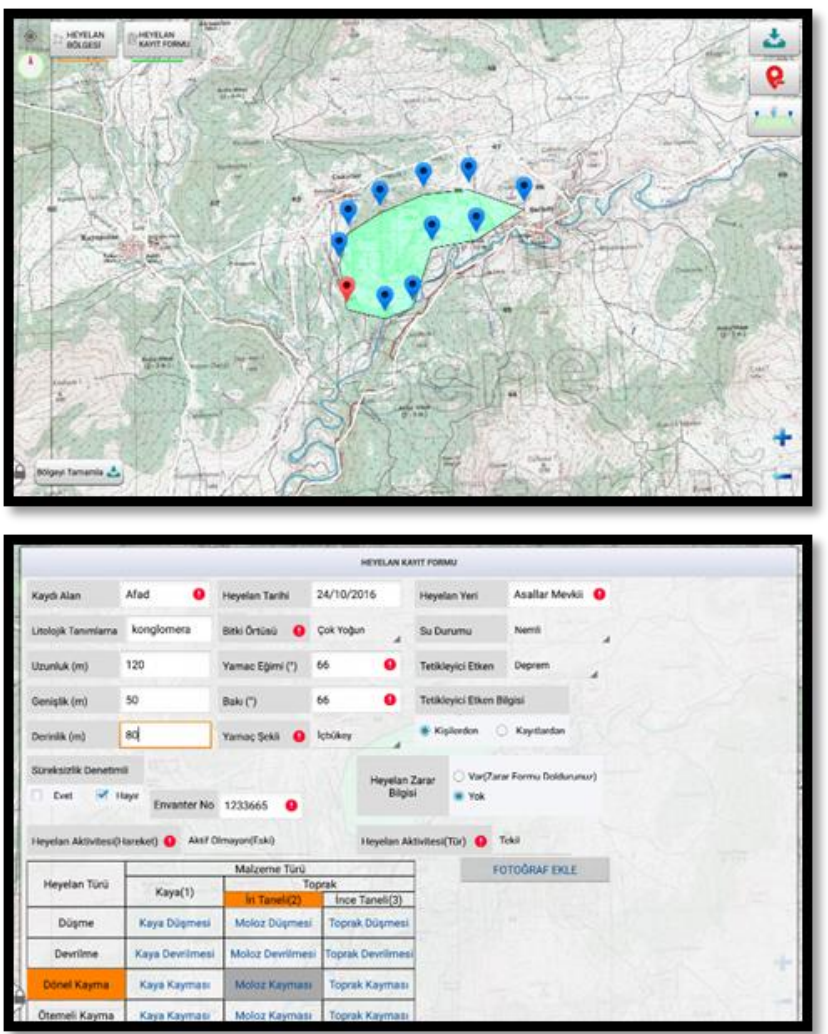

Figure 10. Disaster Event Inventory Data Collection Mobile Application 
- Damage Assessment Mobile Application: On-line and offline, geo-located damage detection data can be collected using damage detection forms in different detail. Unauthorized transactions are prevented by interrogating the personnel information to be assigned to the damage assessment studies during the data entry. In practice, it can be used as a base by taking the roads, important points (parks, public institutions, shopping centres, industrial areas, etc.), topographic maps and satellite images - on-line - on the mobile device memory as well as provincial, district and neighbourhood data. The collected data can be displayed in real-time on the relevant screens of SIS and Recovery components. Figure 11 shows screenshots of this Damage Assessment Mobile Application.
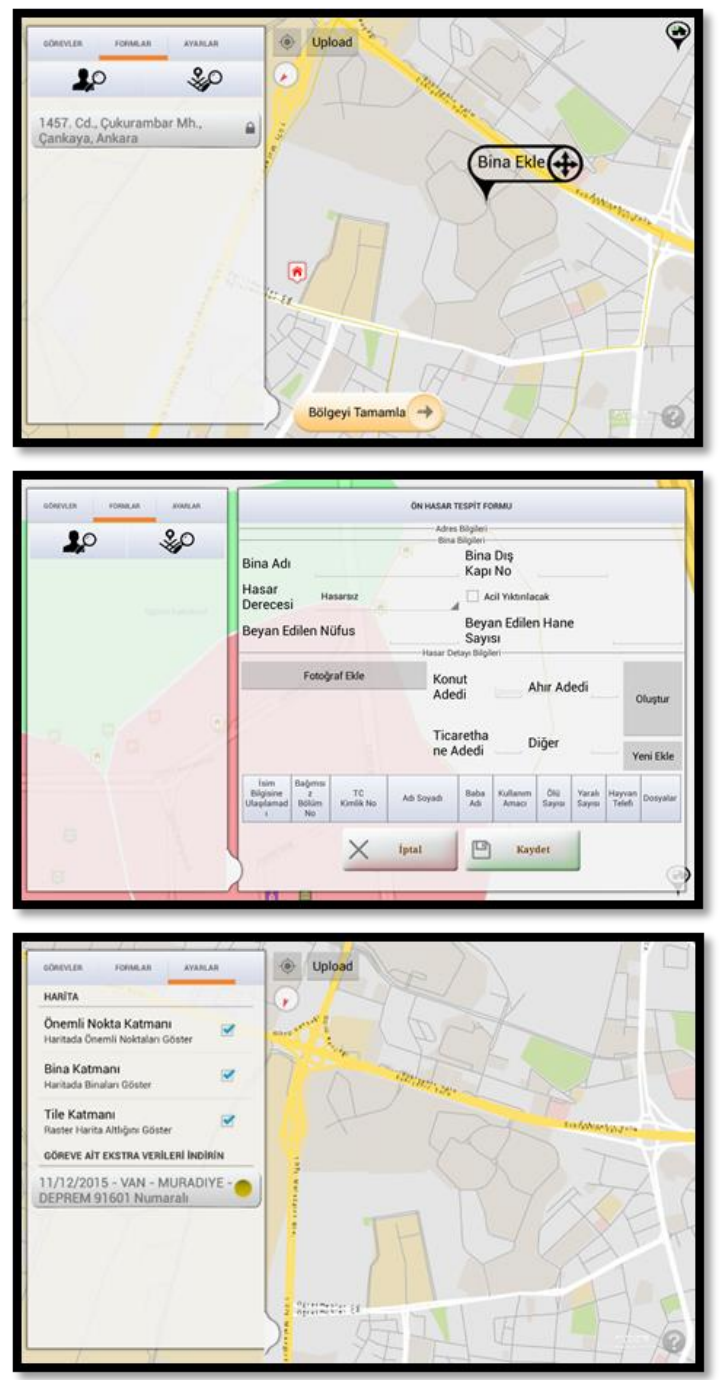

Figure 11. Damage Assessment Mobile Application

Other mobile applications planned to be developed under AYDES are as follows:

- Geological Hazard Survey Reports Mobile Application: Spatial data (survey area, landslide area, area exposed to hazard etc.) determined in geological hazard survey reports and related descriptive data (disaster victim list, disaster situation etc.) will be collected on-line and off-line. The collected data can be displayed on the relevant screens of the SIS and Recovery components in real time.
- Resettlement Site Selection Mobile Application: This software will allow the collection of spatial data (parcel, area, etc. determined for site selection) and relevant descriptive data (feature attribute values) specified in the site selection protocols and works. The collected data can be displayed on the relevant screens of the SIS and Recovery components in real time.

\section{IMAGE PROCESSING ANA ANALYSIS SOFTWARE TOOLS INTEGRATED TO AYDES}

Before or after disasters, it's important to access the needed information urgently and economically for potential analysis about the terrain besides its accuracy and reliability. Herein, remote sensing technology provides an important data source that can be used in disaster management. A lot and various data and evaluations related with disaster event inventory, vulnerable assets, hazard-risk, disaster prone areas, and damage assessment results etc. are needed in context of disaster management and decision support systems. For this purpose, AYDES-RS and AYDES-CS software have been developed to use in processing and evaluating the images provided by remote sensing (space/aerial) technology for several disaster managements related analyses in terms of Disaster and Emergency Management Authority (AFAD)'s needs. Evaluation results are integrated directly to AYDES and shared publicly by AFAD web site.

\subsection{AYDES-RS}

AYDES-RS (AYDES-UZAL in Turkish) is a desktop geospatial imagery analysis and processing that enables synthetic aperture radar (SAR) electro-optic (EO) satellite image / aerial photo processing and analysing. The software is designed especially for AFAD's special needs related with disaster management. Technically, it is developed in Java language by using ESA's open source libraries. Software contains specific applications for identifying preliminary affected area and hazard / damage assessment caused by disasters like earthquake, flood and forest fire. In addition to these, different applications and algorithms also provide change detection, supervised/unsupervised classification, object based image analysis and fabric analysis that are integrated into the software to use for before/after disaster related remote sensing based image analysis. The primary aim of AYDES-RS is to offer an integrated software solution of visualizing, processing, analysing remote sensed data, presenting and exporting results into disaster management and decision support systems (Figure 12, Figure 13).

\subsection{AYDES-CS (Crowd-Sourcing) Platform}

AYDES-CS (AYDES-KITLEKAYNAK in Turkish) is a web based crowd - sourcing platform. Especially, while automatic image processing algorithms produce no results or obtained results need to be confirmed, manual assessment of postdisaster images could be required. For this purpose, post disaster images are divided into little pieces and tiled by the application and then sent to previously identified users called as crowd through the web. Users fulfil their duties by examining the images and marking on them according to type of operation. Same image tile can be sent more than one user. Consequently, system examines the markings of users and produce a final report automatically by using statistical algorithms to evaluate the markings of users. The results might be related with information about number, location of damaged buildings, location of closed roads, wrecks and landslide flood prone areas etc. can be acquirable in minutes (Figure 14). 


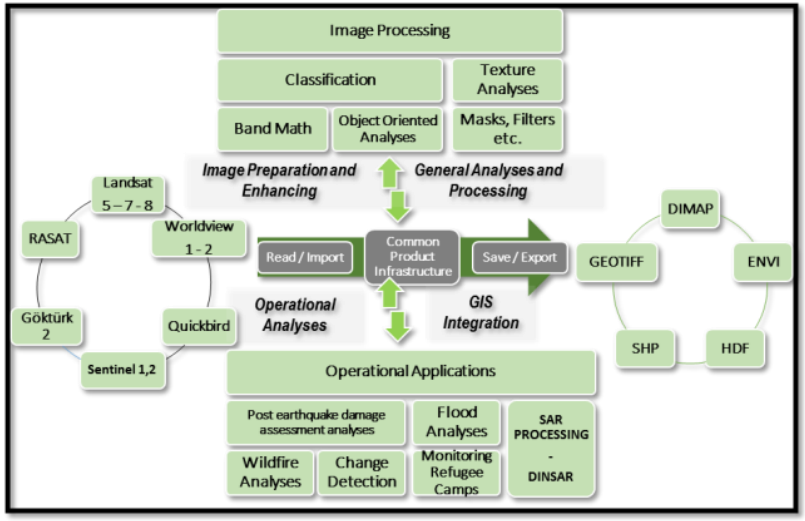

Figure 12. Main functions and product input / output support of AYDES - RS

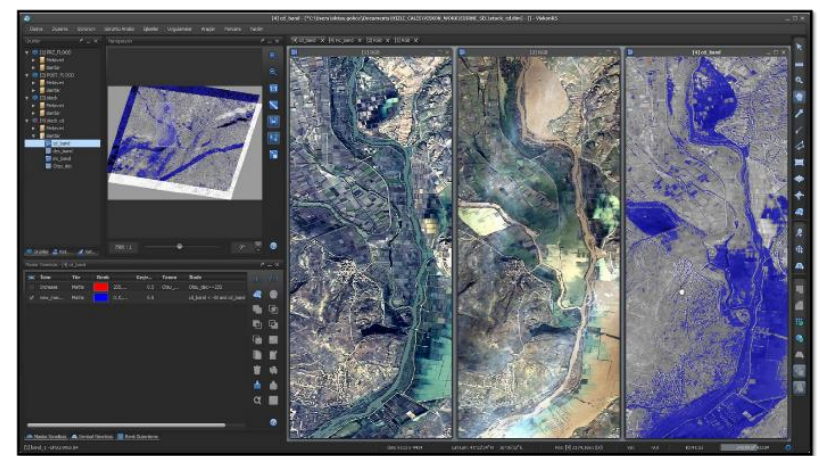

Figure 13. AYDES - RS main screen and menus together with a sample analysis of 2015 Edirne flood event

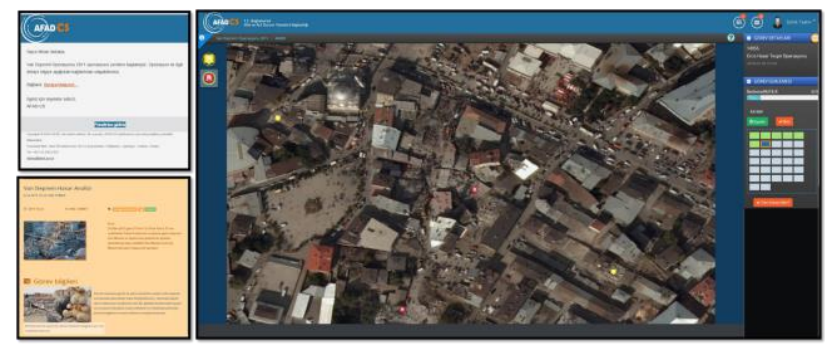

Figure 14. AYDES - CS platform

The crowd of experts or volunteers are informed that they are being charged with a disaster by SMS or e-mail sent automatically by the system to them. They enter the system via their computers or mobile devices and get informed the task assigned to them. For example, the buildings destroyed after an earthquake are quickly marked by the crowd. Each user is given a limited size and number of satellite / aerial image tiles. The same image tile can be evaluated by more than one user. Once users complete the marking, the system evaluates the markings with its own algorithms and provides optimal results. When the results are determined, the user's assessment scores from previous disaster events, stable markings made by different users in the same image tile, etc. are taken into consideration. The examples in Figure 15 show the markings to identify landslide inventory collection (using image tiles with a size $50 \mathrm{x}$ 50 meters) and inventory of buildings damaged by post-disaster floods.

By the help of remote sensing technologies, satellite/aerial image data acquired for large areas could be processed and analysed more quickly and economically. And by using the results of these analyses, favourable results are obtained. In this project, customized remote sensing software tools have been developed in terms of the needs of AYDES. They are developed with the cooperation of AFAD and TUBITAK (The Scientific and Technological Research Council of Turkey).

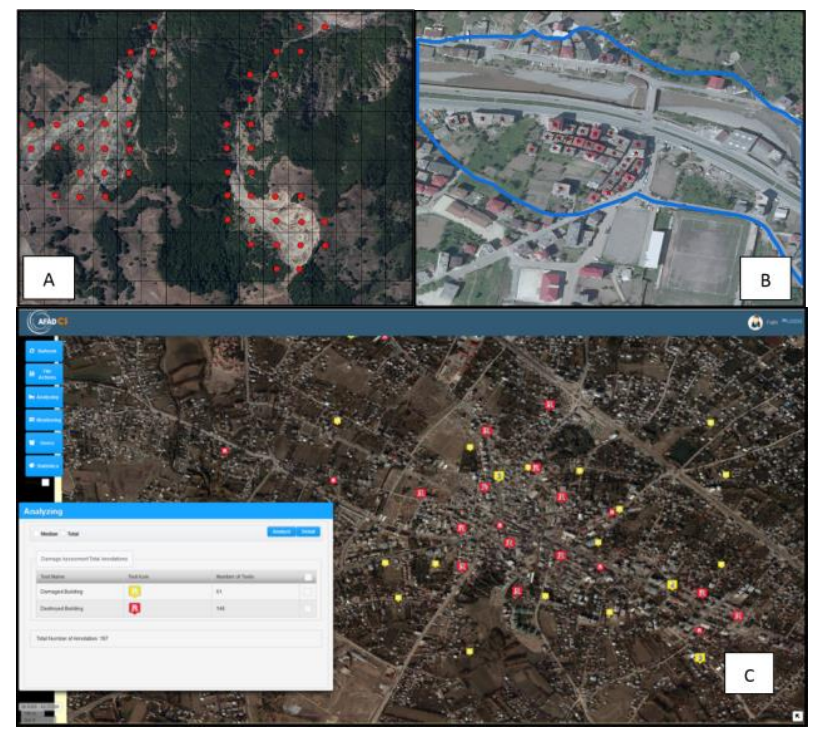

Figure 15. Data collection by an expert/volunteer (for example: digitizing the landslide areas (A) or inventory of buildings damaged by post-disaster floods (B)). The results are integrated to AYDES as a bulk (for example: buildings damaged by earthquake (C)

\section{CONCLUSION}

Through the Disaster Management and Decision Support System (AYDES) project, efforts are being made to establish and sustain an information infrastructure and decision support system centred management model required for the effective management of disaster and emergency management processes. AYDES, including desktop, mobile and web-based applications based on GIS and RS technologies, is an integrated platform connected to many internal and external systems.

This platform, especially Turkey Disaster Response Plan coverage prepared in accordance with AFAD, relevant Ministries, designed to be used by private organizations and provincial organizations, processes active, care is taken to be an integrated framework that allows quick execution. Figure 16 summarizes the procedure at AYDES which is trying to answer briefly about any disaster event.

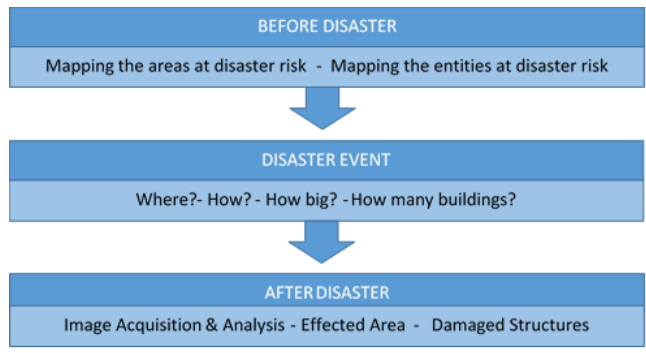

Figure 16: The procedure at AYDES

As a result; within the context of disaster management and decision support system, AYDES is an integrated platform comprising procedures, human resources, data, hardware and software tools which provide accurate and current disaster and emergency data \& information, various reports, statistics, task monitoring, queries and analysis, etc. at all stages before and after a disaster. 